\title{
Hyperhomocysteinemia and its relations to conventional risk factors for cardiovascular diseases in adult Nigerians: the REMAH study
}

\author{
Babangida S. Chori ${ }^{1,2}$, Benjamin Danladi², Bassey A. Inyang ${ }^{1}$, Michael P. Okoh ${ }^{1}$, Maxwell M. Nwegbu',
} Adewale L. Alli ${ }^{1}$ and Augustine N. Odili ${ }^{*}$

\begin{abstract}
Background: Evidence linking homocysteine (Hcy) with cardiovascular diseases (CVD) or its risk factors are limited in a sub-Saharan black population.

Objective: We set out to evaluate the association between Hcy and hypertension and other CVD risk factors in a population of adult Nigerians.

Methods: Data of 156 adults aged 18-70 years was accessed from the North Central study site of the REmoving the MAsk on Hypertension (REMAH) study. Homocysteine, blood glucose and lipid profile in whole blood/serum were measured using standard laboratory methods. Hypertension was diagnosed if average of 5 consecutive blood pressure (BP) measurements obtained using a mercury sphygmomanometer was equal to or higher than 140 systolic and/or $90 \mathrm{mmHg}$ diastolic or the individual is on antihypertensive medication. Hyperhomocysteinemia (HHcy) was defined as Hcy $>10 \mu \mathrm{mol} / \mathrm{L}$.

Results: Of the 156 participants, 72 (43.5\%) were hypertensive, of whom 18 had HHcy. Subjects with HHcy were significantly ( $p<0.05$ ) older (41.5 vs. 40.6yrs), had lower HDL-cholesterol ( 0.6 vs. $0.8 \mathrm{mmol} / \mathrm{L}$ ) and higher systolic (145.5 vs. $126.0 \mathrm{mmHg}$ ) and diastolic BP (92.9 vs. $79.6 \mathrm{mmHg})$, compared to those without HHcy. Intake of alcohol and a $1 \mathrm{yr}$ increase in age were respectively and significantly $(p<0.05)$ associated with a 1.54 and $0.10 \mu \mathrm{mol} / \mathrm{L}$ increase in Hcy. In a multivariable model adjusted for age, sex and body mass index, a $1 \mu \mathrm{mol} / \mathrm{L}$ increase in Hcy, was associated with a $1.69 \mathrm{mmHg}$ and $1.34 \mathrm{mmHg}$ increase in systolic and diastolic pressure $(p<0.0001)$ respectively; and a $0.01 \mathrm{mmol} / \mathrm{L}$ decrease in HDL-cholesterol $(p<0.05)$.
\end{abstract}

Conclusion: HHcy occurs among hypertensive Nigerians and it is independently associated with age, HDL-cholesterol, systolic and diastolic BP.

Keywords: Hyperhomocysteinemia, High-density lipoprotein, Blood pressure, Cardiovascular diseases risk factors

*Correspondence: augustine.odili@uniabuja.edu.ng; odilimercy@yahoo.com

${ }^{2}$ Circulatory Health Research Laboratory, Old Anatomy Block (Beside School of Nursing and Midwifery), University of Abuja Teaching Hospital, Gwagwalada, Abuja, Nigeria

Full list of author information is available at the end of the article

\section{Introduction}

Hypertension is a global health challenge increasingly responsible for most deaths worldwide. According to the Global Disease Burden survey [1], cardiovascular diseases (CVD) account for nearly 17 million deaths annually, of which more than $50 \%$ are due to hypertension related complications. 
In its effort to tackle the rising burden of hypertension globally, the World Health Organisation recommends increase in physical activity, avoidance of unhealthy diet, reduction in salt intake and abstinence from tobacco use and harmful intake of alcohol [2]. Despite adopting these recommendations at population and individual levels, the burden of hypertension and other CVDs remains inadequately addressed, thus underscoring the need to explore other risk factors such as homocysteine.

Homocysteine is an intermediary metabolite of methionine whose amount in excess of $10 \mu \mathrm{mol} / \mathrm{L}$ (otherwise known as hyperhomocysteinemia) increases the risk of CVD in people with hypertension [3]. Compelling evidence from large-scale observational [4] and longitudinal studies [5] indicate that the risk of stroke in subjects suffering from hypertension accompanied by HHcy is higher compared to those with neither/either of the two conditions. Epidemiological data from United States of America, China and Europe indicate that among hypertensive subjects, prevalence of HHcy is $39 \%, 75 \%$, and $19 \%$ respectively. Although the role of homocysteine is well-established in the development of vascular diseases [6,7], efforts to use it as a therapeutic target of hypertension or CVD has suffered major setbacks $[8,9]$. Hypothesis stimulated by recent evidence [10] indicates that the therapeutic benefit of homocysteine lowering may be affected by its interaction with other risk factors for hypertension or CVD, hence may vary from population to population. In Nigeria, $38 \%$ of its adult population are hypertensive, of whom control of blood pressure is achieved only in $12 \%$ [11] and knowledge of the burden of hyperhomocysteinemia is uncertain. The present study was aimed at evaluating the burden of hyperhomocysteinemia among adult Nigerians and also to assess the relation of homocysteine with hypertension and established risk factors for CVD.

\section{Methods}

\section{Sampling/study participants}

Participants of the current study were of a sub-sample of adult Nigerians aged 18 years and above that participated in the Removing the Mask on Hypertension (REMAH) Study $[11,12]$. REMAH was a nationwide study that surveyed hypertension and its risk factors in the six geopolitical zones of Nigeria. From each zone, subjects were drawn from two communities of a state including Anambra, Akwa-Ibom, Oyo, Zamfara, Gombe and FCT-Abuja using a multistaged sampling technique. Communities were sensitized and mobilised, following which houses were systematically numbered, randomly selected and visited to issue invitations to eligible adults aged 18 years and above. Physical examinations were conducted on consenting participants further to which blood samples were collected for biochemical examinations. REMAH strictly complied with the Helsinki Guidelines [13] for conducting research on human subjects. For the purpose of this homocysteine sub-study, we used a prevalence rate of $51 \%$ (from a previous survey of HHcy among adult Nigerians) [14], a margin of error of $8 \%$ and static confidence level of $95 \%$, to determine the sample size sufficiently powered for this study. We estimated a total of 150 subjects. Using a systematic random technique, we selected 156 subjects from the 653 subjects of the FCTAbuja study site whose serial number was a multiple of 4. Subjects were excluded if they reported current use of folic acid, vitamin B6, vitamin B12 supplementation or any lipid lowering medications.

\section{Biochemical examination}

Non-fasting blood samples were collected and the resulting sera stored at $-20{ }^{\circ} \mathrm{C}$ until analysis. Homocysteine was estimated from blood serum using the sandwich enzyme-linked immunoabsorbent (ELISA) assay method of Engvall and Perlmann [15]. Random blood glucose was measured from whole blood using accuchek glucometer ${ }^{\circledR}$. Other biochemical analytes including total cholesterol, high density lipoprotein cholesterol (HDL-C), low density lipoprotein cholesterol (LDL-C) and triacylglycerol (TAG) were estimated at the Circulatory Health Research Laboratory using Landwind $\mathrm{c} 100^{\circledR}$ autochemistry analyser. Analyses were done using ready-to-use reagents obtained from Beijing Strong Biotechnologies incorporation, Haidan District, Beijing China in accordance with manufacturer's guide.

\section{Blood pressure measurement}

Blood pressure was obtained by trained observers using Accoson ${ }^{\circledR}$ mercury sphygmomanometer. Observers received training on blood pressure measurement using the British Hypertension Society Blood Pressure Measurement Educational Video [16]. They measured brachial blood pressure by auscultation of the Korotkoff sounds at the non-dominant arm in accordance with the 2013 guidelines of the European Society of Hypertension (ESH)/European Society of Cardiology (ESC) [17]. Participants were allowed to sit and rest for $5 \mathrm{~min}$ after which 5 BP readings are obtained at an interval of 30 to $60 \mathrm{~s}$. Systolic and phase V diastolic blood pressures are determined to the nearest $2 \mathrm{~mm} \mathrm{Hg}$. Standard cuffs with $12 \times 24 \mathrm{~cm}$ inflatable bladders are used for subjects whose arm circumference is less than $31 \mathrm{~cm}$, and $15 \times 35 \mathrm{~cm}$ for those with arm circumference greater than $31 \mathrm{~cm}$.

A participant's clinic BP is an average of the 5 consecutive BP measurements. 


\section{Definition of terms}

Hypertension was defined according to the $2013 \mathrm{ESH} /$ ESC guidelines [17] as systolic blood pressure $\geq 140 \mathrm{~mm}$ $\mathrm{Hg}$ and/or diastolic blood pressure $\geq 90 \mathrm{~mm} \mathrm{Hg}$ and/or self-reported treatment of hypertension using antihypertensive medications. Hyperhomocysteinemia was defined according to the American Heart Association/ American Stroke Association Council on Stroke as a serum homocysteine greater than $10 \mu \mathrm{mol} / \mathrm{L}$ [18].

\section{Other measurements}

Field officers measured weight and height in kilogram and centimeter respectively, using a stadiometer. Waist and hip circumference were measured in centimeter using a non-stretchable tape. They also administered a modified WHO STEPs Questionnaire to collect information on relevant medical history, alcohol and cigarette consumption, and intake of medications.

\section{Database management and statistical analysis}

We used SAS software version 9.4 (SAS Institute, Cary, NC) for data management and statistical analysis. We used mean and standard deviation to respectively measure the central tendency and dispersion of continuous variables. Differences of means between binary groups were tested using student $\mathrm{t}$-test. We used numbers and percentages to express categorical variables and differences in percentages were tested using chi-square. We regressed serum homocysteine on biochemical, anthropometric, socio-demographic and physiological characteristics to determine their associations. We further tested for Independent association of serum homocysteine with other variables in a multivariable model adjusted for age, sex and BMI. The null hypothesis was rejected for 2-sided values of $\mathrm{P}<0.05$.

\section{Results}

\section{Characteristics of study participants}

Table 1 shows the baseline characteristics of subjects stratified based on their hyperhomocysteinemia status. A total of 156 subjects with an average age of 41.5 years were included in this study. Of the entire subjects, $72(46.2 \%)$ were women, $84(53.8 \%)$ were men and 18 (11.5\%) had hyperhomocysteinemia. In comparison to subjects without hyperhomocysteinemia, subjects with hyperhomocysteinemia had significantly higher $(\mathrm{p}<0.05)$ mean age ( 49.0 vs. $35.0 \mathrm{yrs}$ ), higher mean systolic blood pressure (145.5 vs. $126.0 \mathrm{mmHg}$ ), higher mean diastolic blood pressure (92.9 vs. $79.6 \mathrm{mmHg}$ ) and lower HDL-C (0.6 vs. $0.8 \mathrm{mmol} / \mathrm{L}$ ).

\section{Prevalence of hyperhomocysteinemia}

Hyperhomocysteinemia (HHcy) was prevalent in 11.5\% of the overall subjects; $13.1 \%$ in men, $9.7 \%$ in women and $23.6 \%$ in subjects with hypertension (Fig. 1).

\section{Association of homocysteine with sociodemographic characteristics}

According to Table 2, homocysteine (Hcy) correlated positively with age and alcohol intake. Intake of alcohol and a 1 year increase in age were significantly $(\mathrm{p}<0.05)$ associated with 1.54 and $0.10 \mu \mathrm{mol} / \mathrm{L}$ increase in Hcy respectively. In a multivariable model, mutually adjusted

Table 1 Baseline characteristics of participants

\begin{tabular}{|c|c|c|c|c|}
\hline & Overall & $\mathrm{Hcy}<10 \mu \mathrm{mol} / \mathrm{L}$ & $\mathrm{Hcy} \geq 10 \mu \mathrm{mol} / \mathrm{L}$ & $\mathrm{p}$-Value \\
\hline Number (\%) & 156 & $138(88.5)$ & 18(11.5) & \\
\hline Women & $72(46.2)$ & 65(90.3) & $7(9.7)$ & 0.5109 \\
\hline Men & $84(53.8)$ & 73(86.9) & 11(13.1) & \\
\hline \multicolumn{5}{|l|}{ Mean $\pm S D$} \\
\hline Age & $41.5 \pm 13.6$ & $40.6 \pm 12.9$ & $48.0 \pm 17.0$ & 0.0247 \\
\hline $\mathrm{BMI}, \mathrm{Kg} / \mathrm{m}^{2}$ & $25.5 \pm 5.2$ & $25.5 \pm 5.1$ & $25.4 \pm 6.4$ & 0.9674 \\
\hline WHR & $0.89 \pm 0.09$ & $0.89 \pm 0.09$ & $0.89 \pm 0.07$ & 0.9957 \\
\hline Systolic BP & $128.2 \pm 20.9$ & $126.0 \pm 20.0$ & $145.5 \pm 20.3$ & $<0.0001$ \\
\hline Diastolic BP & $81.1 \pm 13.7$ & $79.6 \pm 13.2$ & $92.9 \pm 11.6$ & $<0.0001$ \\
\hline Random blood glucose & $5.98 \pm 2.08$ & $6.0 \pm 2.0$ & $5.9 \pm 2.4$ & 0.7735 \\
\hline $\mathrm{HDL}-\mathrm{C}, \mathrm{mmol} / \mathrm{L}$ & $0.78 \pm 0.38$ & $0.8 \pm 0.4$ & $0.6 \pm 0.4$ & 0.0103 \\
\hline $\mathrm{LDL}-\mathrm{C}, \mathrm{mmol} / \mathrm{L}$ & $2.04 \pm 0.98$ & $2.0 \pm 1.0$ & $2.2 \pm 1.0$ & 0.5124 \\
\hline $\mathrm{TAG}, \mathrm{mmol} / \mathrm{L}$ & $1.42 \pm 0.68$ & $1.4 \pm 0.7$ & $1.5 \pm 0.4$ & 0.6315 \\
\hline Total Cholesterol, mmol/L & $3.47 \pm 1.06$ & $3.5 \pm 1.0$ & $3.4 \pm 1.0$ & 0.8738 \\
\hline
\end{tabular}




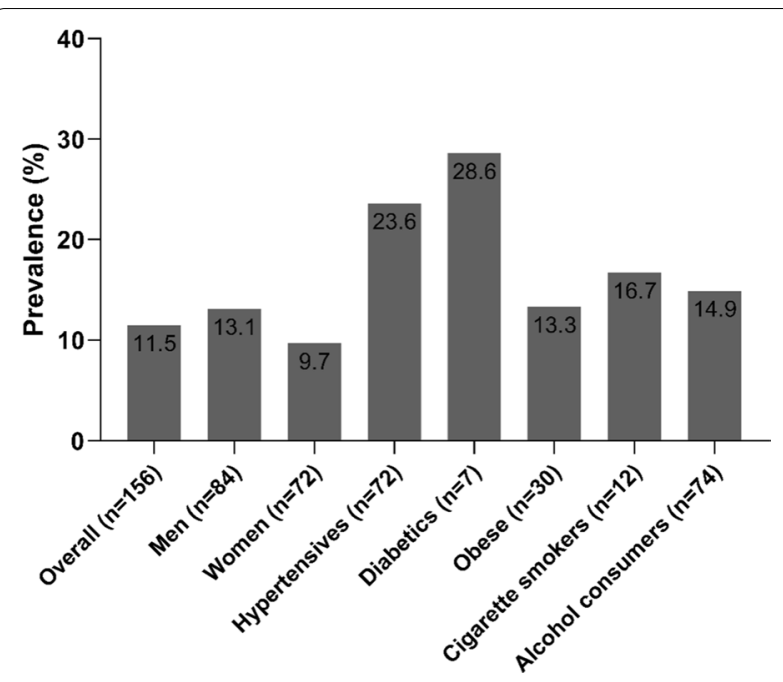

Fig. 1 Prevalence of hyperhomocysteinemia
Table 3 Multivariable linear regression analysis of association of homocysteine with socio-demographic, biochemical and physiological characteristics

\begin{tabular}{lcc}
\hline Characteristics & ${ }^{*} \boldsymbol{\beta}$ value & P value \\
\hline Sociodemographic $^{\mathrm{a}}$ & 0.095 & \\
Age $^{\mathrm{a}}$ & 1.091 & 0.0008 \\
Alcohol Intake $^{b}$ & & 0.1488 \\
Biochemical & -0.015 & \\
HDL-C & 0.013 & 0.0301 \\
TAG $^{c}$ & & 0.2651 \\
Physiological $_{\text {Systolic BPc }}$ & 1.691 & \\
Diastolic BPc & 1.299 & $<0.0001$ \\
\end{tabular}

${ }^{a}$ Adjusted for sex, alcohol intake, cigarette smoking and BMI

b Adjusted for age, sex, cigarette smoking and BMI

c Adjusted for age, sex, cigarette smoking, alcohol intake and BMI

between Hcy and HDL-C remained the same after adjustment for age, sex, BMI, intake of alcohol and cigarette smoking.

of association of homocysteine with sociodemographic,
anthropometric, biochemical and physiological
characteristics

\begin{tabular}{lcr}
\hline & $\boldsymbol{\beta}$ value & P value \\
\hline Socio-demographic & & \\
Age & 0.097 & 0.0005 \\
Sex & 1.015 & 0.1856 \\
Cigarette smoking & 1.755 & 0.2215 \\
Alcohol intake & 1.542 & 0.0442 \\
Body Mass Index & 0.083 & 0.3449 \\
Waist-hip ratio & 0.002 & 0.3200 \\
Biochemical & & \\
LDL & 0.007 & 0.6824 \\
HDL-C & -0.015 & 0.0166 \\
TAG & 0.026 & 0.0252 \\
Total Cholesterol & 0.003 & 0.8568 \\
Blood Glucose & 0.044 & 0.2148 \\
Physiological & & \\
Systolic BP & 2.220 & $<0.0001$ \\
Diastolic BP & 1.564 & 0.0001 \\
Pulse rate & 0.353 & \\
\hline
\end{tabular}

for age, sex and BMI, the relationship remained the same only for age (Table 3).

\section{Association of homocysteine with biochemical characteristics}

A $1 \mu \mathrm{mol} / \mathrm{L}$ increase in Hcy associated positively with triacylglycerol $(\beta=0.03, p=0.0252)$ and negatively with HDL-C $(\beta=-0.02, p=0.0166)$. The relationship

\section{Association of homocysteine with blood pressure}

Increasing Hcy by $1 \mu \mathrm{mol} / \mathrm{L}$ was associated with a corresponding increase of $2.2 \mathrm{mmHg}$ in systolic blood pressure (SBP) and $1.7 \mathrm{mmHg}$ in diastolic blood pressure (DBP). Adjustment for age, sex, BMI, intake of alcohol and cigarette smoking did not alter the association of Hcy and systolic or diastolic BP.

\section{Discussion}

The main finding of this study was that hyperhomocysteinemia (HHcy) occurred in nearly one-eight of the overall subjects and one-quarter of the hypertensive subjects. Homocysteine (Hcy) independently associated with age, high-density lipoprotein cholesterol (HDL-C), systolic and diastolic blood pressure.

Due to the use of different cut-offs for HHcy in different studies, it is difficult to discuss our findings in the light of those of other studies. Our decision to use the $10 \mu \mathrm{mol} / \mathrm{L}$ threshold was driven by expert opinions [19] which suggest that commencement of Hcy reduction at this level is more beneficial than at higher levels. Previous studies of HHcy among hypertensive Nigerians were hospital-based and were done using a threshold of $15 \mu \mathrm{mol} / \mathrm{L}$ $[14,20]$. The prevalence of HHcy among hypertensive subjects in the current study (23.6\%) was strikingly lower than the $56.0 \%$ [20] and $98.3 \%$ [14] reported by the previous studies. Although the cause of this wide difference is unknown, we hypothesise that difference in study participants may be a plausible explanation bearing that subjects of the current study were drawn from an apparently 
healthy semi-urban general population with a socio-economic status that could afford them a vitamin-rich diet well known to protect against HHcy. This hypothesis is based on evidences from large scale observational studies $[21,22]$ which have shown that due to limited financial resources, rural compared to urban dwellers tend to prioritise high-caloric foods over fruits and vegetables given that the former is relatively cheaper. The influence of vitamin-deficient diet on plasma Hcy, possibly explained by low socio-economic status, may also be observed in other surveys involving rural-dwelling Chinese subjects which recorded HHcy in more than $75 \%$ of the hypertensive cohorts [23, 24]. Chang and colleagues reported that among 3392 low-income hypertensive subjects who resided in a rural area of North-Eastern China, more than $85 \%$ had HHcy and an average diet score of 2.2 which is suggestive of a diet pattern low in vegetables. Vitamin B6, B12 and folic acid are essential requirements of Hcy metabolism which when deficient, precipitates an elevation in plasma Hcy. Other reports across the globe have shown that among hypertensive populations, HHcy occurs $39.4 \%$ in the United States of America (USA) [5] and $18.7 \%$ in Europe [25]. In addition to diet, other factors directly influencing plasma Hcy concentration are enzymes responsible for Hcy metabolism such as methylene tetrahydrofolate reductase (MTHFR) [26] and cystathionine beta synthase (CBS) [27] whose defective or variant forms could be involved in geographical/ racial phenotypic variation of HHcy. In the Hordaland homocysteine study including over 18,000 adult Norwegians aged at least 40 years, low folate status accompanied by $\mathrm{Hcy}>40 \mu \mathrm{mol} / \mathrm{L}$ and attributable to the MTHFR $677 \mathrm{C}>\mathrm{T}$ polymorphism was prevalent in over $78 \%$ of the study participants [28]. In some parts of North America such as Canada, the MTHFR $677 \mathrm{C}>\mathrm{T}$ polymorphism accounts for elevated Hcy in almost $40 \%$ of Franco-Canadians and ranges between 5 and $15 \%$ of the general Canadian population [29].

The relation of Hcy with lipid fractions remains largely inconsistent across various observational and experimental studies [27, 30, 31]. Nevertheless, our findings were in concordance with some earlier reports. Evidence from a cross-sectional survey of 4,660 Chinese subjects in Shijingshan district of Beijing [31], showed that increasing Hcy was associated with an increased risk of low HDL-C $(\mathrm{AOR}=1.41,95 \% \mathrm{CI}$ 1.14-1.73) and hypertriglyceridemia $(A O R=1.29,95 \%$ CI $1.10-1.52)$. In 300 Indian patients with coronary heart disease, Mahalle and colleagues [32] reported that Hcy was directly proportional to TAG and VLDL but inversely proportional to HDL-C. Experimental studies involving the use of double knockout mice model (CBS-/-/apo-E-/-) with reduced CBS activity showed lower HDL-C (19.9md/dl vs. $24.4 \mathrm{mg} / \mathrm{dl})$ and higher Hcy $(210 \mu \mathrm{M}$ vs. $3.8 \mu \mathrm{M})$ when compared with single knock-out (CBS $+/+/$ apo-E-/-) [27]. The mechanism underlying the unfavourable association of Hcy with lipid fractions involves various transcription factors and enzymes of lipid metabolism including peroxisome proliferator-activated receptor alpha (PPAR $\alpha)$, lecithincholesterol acyl transferase (LCAT) and sterol regulatory element binding proteins (SREBPs). Hcy interrupts the transcriptional activities of PPAR $\alpha$, thereby down regulating the production of apo-AI which is an indispensable component of HDL-C production and biological activity [33]. It is also most probable Hcy interruption/disruption plays some significant roles in the co-regulation of some downstream retrotransposons such as transposable elements (TEs), repetitive sequences in mammalian genomes, which have been implicated in many of the same conditions for which PPAR $\alpha$ agonists are therapeutic including neuro-degeneration, schizophrenia, and drug addiction. Furthermore, Hcy also interferes with HDL-C production by inhibiting the activity of LCAT [34, 35] which is essential for reverse cholesterol transport. Conversely, Hcy enhances the expression of SREBPs, a membrane bound transcriptional factor of the endoplasmic reticulum which encodes enzymes of cholesterol/TAG metabolism and uptake [36]. These biochemical mechanisms explaining the interaction between Hcy and lipid metabolism are consistent with the results of this study.

Though there are mixed views concerning the link between Hcy and blood pressure [10, 28, 37-39], various mechanisms in support of a positive association have been put forward $[6,40,41]$. Under conditions of HHcy, uptake and synthesis of cysteine (an essential precursor of gluthathione) is reduced and antioxidant potential compromised thus leading to oxidative stress [42]. Additionally, Hcy is also metabolised into Hcy-thiolactone, a reactive specie which when bound to collagen, inhibits its activity [7]. The resultant effect of these is endothelial damage, endothelium-myocyte uncoupling, hindered passage of nitric oxide through the matrix barrier, poor vasodilation, diastolic dysfunction and high blood pressure $[6,40]$. Other possible mechanisms include increased arterial stiffness, increased arteriolar constriction, increased sodium reabsorption, poor elastic vascular wall and smooth cell proliferation [6]. In a case-controlled study involving 2,615 Chinese subjects, Yang and colleagues [10] observed a strong positive correlation between Hcy and blood pressure $(P<0.05)$. Similarly, report from the third National Health and Nutrition Examination Survey (NHANES III) including 7,612 residents of USA aged 17 and above, showed that after adjusting for CVD risk factors, a $5 \mu \mathrm{mol} / \mathrm{L}$ increase in Hcy was associated with a $0.7 \mathrm{mmHg}$ and $0.5 \mathrm{mmHg}$ 
increase in systolic and diastolic BP in men and a $1.2 \mathrm{mmHg}$ and $0.7 \mathrm{mmHg}$ increase in systolic and diastolic BP in women [43]. Contrary to these, the Framingham Heart Survey, documented that after a median follow up of 2,104 subjects for 4 years, the age and sexadjusted odds of hypertension incidence due to Hcy was negative and non-significant [38].

Positive association of Hcy with age or alcohol intake have been widely reported $[14,28,31]$. Though the mechanism underlying this association is vague, it is hypothesized that deficiency in folate and vitamin B12; metabolic changes, poor nutritional absorption and organ function associated with ageing or alcohol intake are possible causes of this anomaly [44-46].

In conclusion, HHcy occurs among adult Nigerians living with hypertension. Hcy associates independently with age, HDL-C, office systolic and diastolic BP. The inverse association of Hcy with HDL-C is clinically relevant considering the vital role that HDL-C plays to prevent against vascular diseases. In addition to this, HDL-C is understood to be crucially involved in the hydrolytic activity of paraoxonase- 1 which leads to breakdown of Hcy-thiolactone (the Hcy derivative that is directly responsible for collagen damage) [47].

Our findings support the need for future research to conduct a pre-assessment of study population with a view to discovering the presence of interactive effects of Hcy and conventional risk factors on hypertension or CVD. This exercise is important as it is hypothesised that the presence of interactive effects of Hcy and other factors may exacerbate the association of Hcy with blood pressure, thus affecting how different populations respond to Hcy-lowering therapy.

Despite conflicting evidence regarding the CVD benefit of lowering plasma Hcy, which has hindered global adoption of Hcy guidelines in CVD care, routine assessment of Hcy in hypertensive subjects is necessary as emerging evidence [48] indicate that Hcy attenuates the efficacy of certain antihypertensive medications like angiotensin converting enzyme inhibitors. The therapeutic benefit of lowering Hcy remains a prospect if the PPAR $\alpha$-induced deregulation of apo-AI can be exploited because animalbased evidence indicates that certain PPAR $\alpha$ agonists such as ciprofibrate improve endothelial function in mice with HHcy [49].

\section{Strengths and limitations}

Given the small size of our sample, caution may be required when translating our findings to the general adult population of Nigeria. However, our subjects were drawn from a well-delineated area of Abuja, a cosmopolitan city with ethnically diverse population that has a semblance of the general Nigerian population. Our study was cross-sectional in design, hence the cause-effect association of Hcy with other factors could not be ascertained. Additionally, the renal function of the study participants which was not examined may have biased either the prevalence of HHcy or the association of Hcy with the selected risk factors of CVD.

\section{Supplementary information}

The online version contains supplementary material available at https://doi. org/10.1186/s12872-021-01913-x.

Additional file 1. Supplementary appendix REMAH Survey Questionnaire.

\section{Abbreviations}

AOR: Adjusted odds ratio; BMI: Body mass index; CBS: Cystathionine $\beta$-synthase; Cl: Confidence interval; CVD: Cardiovascular diseases; DBP: Diastolic blood pressure; FCT-Abuja: Federal capital territory-Abuja; Hcy: Homocysteine; HDL-C: High-density lipoproteins Cholesterol; HHcy: Hyperhomocysteinemia; LCAT: Lecithin-cholesterol acyl transferase; LDL-C: Low-density lipoproteins Cholesterol; MTHFR: Methylene tetrahydrofolate reductase; OR: Odds ratio; PPARa: Peroxisome proliferator-activated receptor a; SBP: Systolic blood pressure; SREBPs: Sterol regulatory element binding proteins; REMAH: REmoving the MAsk on Hypertension; TAG: Triacylglycerol; NHANES III: National health and Nutrition examination survey III; VLDL: Very low-density lipoproteins.

\section{Acknowledgements}

The authors gratefully acknowledge the effort of Mrs. Maureen Amaechi who provided valuable administrative and clerical support to the REMAH project.

\section{Authors' contributions}

The study was conceptualized and designed by Odili AN, Alli LA and Chori BS. Data collection was conducted and overseen by Chori BS, Odili AN, Danladi $B$ and Nwegbu MM. Manuscript was written by Chori BS and revised by Odili AN, Alli LA, Okoh MP and Inyang BA. All authors read and approved the final manuscript.

\section{Funding}

This research was funded by the Tertiary Education Trust Fund (TETFUND) National Research Fund (NRF batch IV).

\section{Availability of data and materials}

The datasets used and/or analysed during the current study are available from the corresponding author on reasonable request.

\section{Ethics approval and consent to participate}

All participants gave informed consent to participate and the study was approved by the University of Abuja Teaching Hospital Ethical research committee.

\section{Consent for publication}

Not applicable.

\section{Competing interests}

None of the authors declares a conflict of interest.

\section{Author details}

${ }^{1}$ Department of Medical Biochemistry, Faculty of Basic Medical Sciences, College of Health Sciences, University of Abuja, Abuja, Nigeria. ${ }^{2}$ Circulatory Health Research Laboratory, Old Anatomy Block (Beside School of Nursing and Midwifery), University of Abuja Teaching Hospital, Gwagwalada, Abuja, Nigeria. ${ }^{3}$ Department of Chemical Pathology, College of Health Sciences, Faculty of Basic Clinical Sciences, University of Abuja, Abuja, Nigeria. 
Received: 24 November 2020 Accepted: 2 February 2021

Published online: 18 February 2021

\section{References}

1. Murray CJ, Aravkin AY, Zheng P, et al. Global burden of 87 risk factors in 204 countries and territories, 1990-2019: a systematic analysis for the Global Burden of Disease Study 2019. 2020:396(10258):1223-1249.

2. WHO. A Global Brief on Hypertension, World Health Day 2013

3. Ganguly P, Alam SF. Role of homocysteine in the development of cardiovascular disease. Nutr J. 2015;14:6.

4. Wu Y, Huxley R, Li L, et al. Prevalence, awareness, treatment, and control of hypertension in China: data from the China National Nutrition and Health Survey 2002. Circulation. 2008;118(25):2679-86.

5. Towfighi A, Markovic D, Ovbiagele B. Pronounced association of elevated serum homocysteine with stroke in subgroups of individuals: a nationwide study. J Neurol Sci. 2010;298(1-2):153-7.

6. van Guldener C, Nanayakkara PW. Stehouwer CDJChr Homocysteine and blood pressure. 2003;5(1):26

7. Perla-Kajan J, Utyro O, Rusek M, Malinowska A, Sitkiewicz E, Jakubowski $\mathrm{H}$. N-Homocysteinylation impairs collagen cross-linking in cystathionine beta-synthase-deficient mice: a novel mechanism of connective tissue abnormalities. FASEB J. 2016:30(11):3810-21.

8. Bonaa KH, Njolstad I, Ueland PM, et al. Homocysteine lowering and cardiovascular events after acute myocardial infarction. N Engl J Med. 2006;354(15):1578-88.

9. Investigators HOPEH. Homocysteine Lowering with Folic Acid and B Vitamin in Vascular Disease. 20063432006

10. Yang B, Fan S, Zhi X, et al. Interactions of homocysteine and conventional predisposing factors on hypertension in Chinese adults. J Clin Hypertens (Greenwich ). 2017;19(11):1162-70.

11. Augustine N. ODILI BSC, Benjamin DANLADI, Peter C. NWAKILE, Innocent C. OKOYE, Umar ABDULLAHI, Maxwell N. NWEGBU, Kefas ZAWAYA, Ime ESSIEN, Kabiru SADA, John O. OGEDENGBE, Akinyemi AJE, Godsent ISIGUZO. Prevalence, Awareness, Treatment and Control of Hypertension in Nigeria: Data from a nationwide survey 2017. Glob Heart. 2020;15(1):47.

12. Nwakile PC, Chori BS, Danladi B, et al. Removing the mask on hypertension (REMAH) study: Design; quality of blood pressure phenotypes and characteristics of the first 490 participants. Blood Press. 2019:1-10.

13. World Medical Association Declaration of Helsinki: Recommendations Guiding Physicians in Biomedical Research Involving Human Subjects. JAMA; 3/19/1997, 1997.

14. Onyemelukwe OU, Maiha BB. Prevalence of hyperhomocysteinaemia, selected determinants and relation to hypertension severity in NorthernNigerian hypertensives: the ABU homocysteine survey. Ghana Med J. 2020;54(1):17-29.

15. Engvall E, Perlmann P. Enzyme-linked immunosorbent assay, Elisa. 3. Quantitation of specific antibodies by enzyme-labeled anti-immunoglobulin in antigen-coated tubes. J Immunol. 1972;109(1):129-135.

16. BHS DVD on BP Measurement. 2007; https://bihsoc.org/wp-content/ uploads/2017/10/BHS-DVD.avi.

17. Mancia G, Fagard R, Narkiewicz K, et al. 2013 ESH/ESC guidelines for the management of arterial hypertension: the Task Force for the Management of Arterial Hypertension of the European Society of Hypertension (ESH) and of the European Society of Cardiology (ESC). Eur Heart J. 2013:34(28):2159-219.

18. Sacco RL, Adams R, Albers G, et al. Guidelines for prevention of stroke in patients with ischemic stroke or transient ischemic attack: a statement for healthcare professionals from the American Heart Association/American Stroke Association Council on Stroke: co-sponsored by the Council on Cardiovascular Radiology and Intervention: the American Academy of Neurology affirms the value of this guideline. 2006;113(10):e409-49.

19. McCully KS. Homocysteine, vitamins, and vascular disease prevention. Am J Clin Nutr. 2007:86(5):1563s-8s.

20. Ajuluchukwu A, Oluwatowoju I, Adebayo K, Onakoya AJWJLSMR. Plasma Total Homocysteine in Diverse Cardiovascular Diseases in Urban Africans. 2011;1:126-32

21. Marie T. Ruel NM, Lisa Smith. Patterns and Determinants of Fruit and Vegetable Consumption in sub-Saharan Africa: A Multicountry Comparison. International Food Policy Research Institute;2005.
22. Miller V, Yusuf S, Chow CK, et al. Availability, affordability, and consumption of fruits and vegetables in 18 countries across income levels: findings from the Prospective Urban Rural Epidemiology (PURE) study. Lancet Global Health. 2016;4(10):e695-703.

23. Guo S, Pang H, Guo H, et al. Ethnic differences in the prevalence of high homocysteine levels among low-income rural Kazakh and Uyghur adults in far western China and its implications for preventive public health. Health. 2015;12(5):5373-85.

24. Chang Y, Li Y, Guo X, Chen Y, Dai D, Sun Y. The Prevalence of Hypertension Accompanied by High Homocysteine and its Risk Factors in a Rural Population: A Cross-Sectional Study from Northeast China. Int J Environ Res Public Health. 2017;14(4).

25. de Bree A, van der Put NM, Mennen LI, et al. Prevalences of hyperhomocysteinemia, unfavorable cholesterol profile and hypertension in European populations. Eur J Clin Nutr. 2005;59(4):480-8.

26. Ilhan N, Kucuksu M, Kaman D, Ilhan N, Ozbay Y. The 677 C/T MTHFR polymorphism is associated with essential hypertension, coronary artery disease, and higher homocysteine levels. Arch Med Res. 2008;39(1):125-30

27. Wang $H$, Jiang $X$, Yang $F$, et al. Hyperhomocysteinemia accelerates atherosclerosis in cystathionine beta-synthase and apolipoprotein $E$ double knock-out mice with and without dietary perturbation. Blood. 2003;101(10):3901-7.

28. Refsum H, Nurk E, Smith AD, et al. The Hordaland Homocysteine Study: A Community-Based Study of Homocysteine, Its Determinants, and Associations with Disease. The Journal of Nutrition. 2006;136(6):1731S-1740S.

29. Arruda VR, von Zuben PM, Chiaparini LC, Annichino-Bizzacchi JM, Costa FFJT, haemostasis. The mutation Ala677 $\rightarrow$ Val in the methylene tetrahydrofolate reductase gene: a risk factor for arterial disease and venous thrombosis. 1997:77(05):0818-0821.

30. Yadav AS, Bhagwat VR, Rathod IM. Relationship of plasma homocysteine with lipid profile parameters in ischemic heart disease. Indian J Clin Biochem. 2006;21(1):106-10.

31. Momin M, Jia J, Fan F, et al. Relationship between plasma homocysteine level and lipid profiles in a community-based Chinese population. Lipids Health Dis. 2017;16(1):54.

32. Mahalle N, Kulkarni MV, Garg MK, Naik SS. Vitamin B12 deficiency and hyperhomocysteinemia as correlates of cardiovascular risk factors in Indian subjects with coronary artery disease. J Cardiol. 2013;61(4):289-94.

33. Mikael LG, Genest J Jr, Rozen R. Elevated homocysteine reduces apolipoprotein A-l expression in hyperhomocysteinemic mice and in males with coronary artery disease. Circ Res. 2006;98(4):564-71.

34. Namekata K, Enokido Y, Ishii I, Nagai Y, Harada T, Kimura H. Abnormal lipid metabolism in cystathionine beta-synthase-deficient mice, an animal model for hyperhomocysteinemia. J Biol Chem. 2004;279(51):52961-9.

35. Velez-Carrasco W, Merkel M, Twiss CO, Smith JD. Dietary methionine effects on plasma homocysteine and HDL metabolism in mice. J Nutr Biochem. 2008;19(6):362-70.

36. Horton JD, Shimomura I. Sterol regulatory element-binding proteins: activators of cholesterol and fatty acid biosynthesis. Curr Opin Lipidol. 1999;10(2):143-50.

37. McMahon JA, Skeaff CM, Williams SM, Green TJ. Lowering Homocysteine with B Vitamins Has No Effect on Blood Pressure in Older Adults. The Journal of Nutrition; 5/1/2007, 2007

38. Sundström J, Sullivan L, D'Agostino RB, et al. Plasma homocysteine, hypertension incidence, and blood pressure tracking: the Framingham Heart Study. Hypertension. 2003;42(6):1100-5.

39. Sutton-Tyrrell K, Bostom A, Selhub J, Zeigler-Johnson C. High homocysteine levels are independently related to isolated systolic hypertension in older adults. Circulation. 1997;96(6):1745-9.

40. C.Tyagi USaS. Homocysteine and Hypertension in Diabetes: Does PPAR? Have a Regulatory Role? PPAR Research. 2010;2010.

41. Stehouwer CD, van Guldener CJCC, Medicine L. Does homocysteine cause hypertension? 2003;41(11):1408-1411.

42. Veeranki S, Tyagi SC. Defective homocysteine metabolism: potential implications for skeletal muscle malfunction. Int J Mol Sci. 2013;14(7):15074-91.

43. Lim U, Cassano PA. Homocysteine and blood pressure in the Third National Health and Nutrition Examination Survey, 1988-1994. Am J Epidemiol. 2002;156(12):1105-13. 
44. Janson JJ, Galarza CR, Murua A, et al. Prevalence of hyperhomocysteinemia in an elderly population. Am J Hypertens. 2002;15(5):394-7.

45. El-Sammak M, Kandil M, El-Hifni S, Hosni R, Ragab M. Elevated plasma homocysteine is positively associated with age independent of C677T mutation of the methylenetetrahydrofolate reductase gene in selected Egyptian subjects. Int J Med Sci. 2004;1 (3):181-92.

46. Halsted CH, Villanueva JA, Devlin AM, Chandler CJ. Metabolic interactions of alcohol and folate. J Nutr. 2002;132(8 Suppl):2367S-2372S.

47. Domagala TB, Lacinski M, Trzeciak WH, Mackness B, Mackness MI, Jakubowski $H$. The correlation of homocysteine-thiolactonase activity of the paraoxonase (PON1) protein with coronary heart disease status. Cell Mol Biol (Noisy-le-grand). 2006;52(5):4-10.
48. Qin X, Li Y, Sun N, et al. Elevated Homocysteine Concentrations Decrease the Antihypertensive Effect of Angiotensin-Converting Enzyme Inhibitors in Hypertensive Patients. Arterioscler Thromb Vasc Biol. 2017;37(1):166-72.

49. Sood HS, Hunt MJ, Tyagi SC. Peroxisome proliferator ameliorates endothelial dysfunction in a murine model of hyperhomocysteinemia. Am J Physiol Lung Cell Mol Physiol. 2003;284(2):L333-341.

\section{Publisher's Note}

Springer Nature remains neutral with regard to jurisdictional claims in published maps and institutional affiliations.
Ready to submit your research? Choose BMC and benefit from:

- fast, convenient online submission

- thorough peer review by experienced researchers in your field

- rapid publication on acceptance

- support for research data, including large and complex data types

- gold Open Access which fosters wider collaboration and increased citations

- maximum visibility for your research: over $100 \mathrm{M}$ website views per year

At BMC, research is always in progress.

Learn more biomedcentral.com/submissions 